\title{
A AVALIAÇÃO NA EDUCAÇÃO BÁSICA ENTRE DOIS MODELOS*
}

\author{
Elba Siqueira de Sá Barretto**
}

\begin{abstract}
RESU M 0 : Este texto visa aprofundar a análise de alguns modelos de avaliação propostos para o ensino básico. Parte de constatações a que chegou estado da arte versando sobre artigos de periódicos acadêmicos acerca do tema no Brasil, nos anos 90, e acrescenta outras reflexões. Constata que fundamentalmente dois modelos vêm povoando 0 discurso sobre a avaliação no país: um que se reporta à sua potencialidade emanci padora e outro que deita raízes na função reguladora do Estado. Procura examiná-los em termos das suas matrizes teóricas e ideológicas e discute questões que deles decorrem. Conclui pela necessidade de repensar, a partir de nova ótica, as funções reguladora e emancipadora da aval iação.

Palavras-chave: Avaliação; M onitoramento; Ensino básico; Q ualidade do ensino; Políticas públicas.
\end{abstract}

Tendo em conta o papel central que a avaliação tem assumido na formulação e implementação das políticas públicas de educação, este artigo propõe-se a aprofundar a análise de alguns referenciais e modelos que a tem informado e discute questões que deles decorrem.

0 texto explora algumas constatações de estudo realizado sobre a produção acadêmica acerca da avaliação na educação básica no Brasil, publicada em dez periódicos nacionais entre 1990 e 1998 (Barretto \& Pinto, 2000), e a elas acrescenta outras reflexões, feitas com base em fontes de natureza diversa.

Entre os pouco mais de 200 textos localizados no referido estudo, chama a atenção a presença majoritária de artigos que versam sobre idéias,

* Este texto constitui versão reformulada de trabalho originalmente apresentado no GT "Estado e Política Educacional" da Anped, durante a 24 a Reunião Anual da Entidade, em Caxambu, $M$ inas G erais, set. 2000.

* Professora da Faculdade de Educação da USP e da Fundação Carlos Chagas. E-mail: essb@fcc.org.br 
conceitos, pressupostos, tendências da avaliação, revelando uma preocupação da área com o esclarecimento dos significados da avaliação no contexto educacional brasileiro. D esses artigos emergem fundamentalmente dois modelos que vêm povoando o discurso sobre a avaliação entre nós.

\section{A aval iação da qualidade do ensino: pressupostos multi-referenciados}

A mais numerosa produção da literatura examinada sobre o ensino básico dedica-se a discutir questões ligadas ao estatuto científico da avaliação da qualidade do ensino. A escassez de teorias sobre avaliação propriamente dita não impede o esforço de elucidar pressupostos da filosofia e de ciências como a Sociologia, Psicologia, Antropologia e da própria Pedagogia, aos quais se filiam concepções de educação de que derivam, por sua vez, diferentes concepções de avaliação.

É freqüente que critiquem genericamente o paradigma positivista predominante na tradição de avaliação brasileira, sendo que a partir de várias vertentes teóricas, nem sempre claramente explicitadas e nunca aprofundadas, acabam por esboçar características de um novo modelo de avaliação apresentado como desejável.

Tais características são bastante convergentes, indicando haver já um amplo consenso na área. Elas passam pela defesa de uma abordagem historicamente situada, que, em relação ao aluno, leve em conta não apenas a dimen são cognitiva, mas a social, a afetiva, seus val ores, motivações e até mesmo a sua própria história de vida. A busca da possibilidade de avaliar a qualidade do ensino faz recair a ênfase nas variáveis do processo, muito mais do que no produto da educação, sendo que a sua natureza deveser eminentemente dialógica edialética, voltada para a transformação, tanto no plano pessoal como no social. A avaliação deve ter um caráter contínuo, que supõe trocas constantes entre avaliador e avaliado, o que pode implicar, dependendo do nível de ensino, maior interação com as próprias famílias dos educandos, especialmente no caso das crianças menores. As mudanças em relação ao indivíduo apontam na direção da autonomia e, em relação ao social, na direção de uma ordenação democrática e, portanto, mais justa da sociedade.

0 eixo da avaliação deixa de girar exclusivamente em torno do aluno e da preocupação técnica de medir o seu rendimento. Passa a centrar as atenções em torno das condições em que é oferecido o ensino, formação do professor e suas condições de trabalho, currículo, cultura e organização da escola e, ainda, postura de seus dirigentes e demais agentes educacionais. 
Essa mudança de enfoque, que explora sobretudo as relações intermediárias entre as análises macro-estruturais e as abordagens micro, vem possibilitando a paulatina superação da tradição crítico-reprodutivista. Esta última tradição, muito tendo contribuído para elucidar os condicionantes estruturais da educação e o papel da avaliação na manutenção da ordem social vigente, gerou, como já assinalaram estudos anteriores, uma produção sobre o tema com acentuada conotação de denúncia, mas pouco subsidiou a proposição de enfoques alternativos.

Entre os textos que trazem o foco da avaliação para a escola e, em menor proporção, para o professor e outros atores educacionais, incluemse algumas proposições acerca das análises institucionais. Assim como em relação ao aluno e aos agentes educacionais, a proposta de avaliação institucional enfatiza o diálogo, a participação, a elaboração coletiva das propostas de mudança, o estabelecimento de relações menos fortemente hierarquizadas e mais democráticas entre as instâncias.

0 paradigma emergente de avaliação qualitativa não tem uma densidade teórica própria. Ele empresta elementos de várias vertentes de pensamento, constituindo-se numa formulação multidisciplinar. Os textos que a ele se referem, embora não se pretendam prescritivos, representam, no mais das vezes, afirmações de princípios genéricos acerca de orientações que se deseja sejam adotadas, sendo pouco freqüentes aqueles que refletem sobre ações desenvolvidas sob tais princípios ou orientações.

A seleção de alguns excertos de artigos representativos da bibliografia pesquisada pode oferecer idéia mais precisa das formulações sobre 0 modelo.

Luckesi $(1991,1992,1996)$, autor muito citado entre os educadores a propósito do tema, procura contribuir para a elucidação dos pressupostos filosóficos e educacionais das práticas avaliativas no ensino básico, insistindo na necessidade de qualificar a avaliação não em função dela mesma, mas do fim a que se destina, e mostrando que esta, ao conquistar ao longo dos tempos espaço tão amplo nos processos de ensino, condicionou a prática pedagógica ao que ele chama pedagogia do exame. D iscute ainda a relação entre planejamento, avaliação eprojeto pedagógico da escola, ressaltando a dimensão política que possuem essas atividades e preconizando um trabalho de equipe em que todos decidem o que e como fazer para elaborar uma proposta coerente com as necessidades da clientela.

M aria Laura Franco (1990) faz, por sua vez, uma caracterização sumária das matrizes epistemológicas dos modelos de ciência que privilegiam seja o objeto, seja o sujeito. Transpostos para a avaliação educa- 
cional, tais model os teriam representado um avanço e nortearam a geração de paradigmas mais complexos e abrangentes. No entanto, como em ambos os casos a visão do indivíduo se apresenta de forma abstrata, a autora dá ênfase à necessidade de que a avaliação educacional tenha como unidade de análise o vínculo indivíduo-sociedade numa dimensão histórica. D aí ser fundamental para a avaliação da aprendizagem em todos os níveis o entendimento da atividade humana, da ação prática dos homens, o que pressupõe a análise do motivo e da finalidade dessa ação.

Em outro ensaio, Franco (1994) aponta ainda para a complexidade do conceito de qualidade do ensino, considerando-o como um produto histórico e social que reflete um posicionamento político e ideológico orientado por diferentes expectativas, que incorporam demandas diversificadas e mutáveis ao longo do tempo. Ao discutir critérios de avaliação e indicadores de qualidade, questiona a validade daqueles que são pensados em função do mito da modernidade, que os elege sobretudo pelas exigências da produção.

Um considerável número de textos, ao acentuar os aspectos políticos e histórico-sociais da avaliação, apoia-se predominantemente nos referenciais de $\mathrm{H}$ abermas para propor a avaliação do tipo emancipatório dentro de um paradigma dialético. Entre eles os mais representativos são os de Pedro $D$ emo. Tendo em conta o fato de que os aspectos políticos da educação têm a ver com o exercício da cidadania, esses textos propõem uma estratégia de formação de sujeitos sociais, dotados de capacidade para se autodefinirem, bem como para determinarem o seu destino histórico, de modo tal que logrem conceber e construir sua emancipação política e econômica, assim como o seu projeto de desenvolvimento como povo.

D emo (1990), após admitir que a quantidade e a qualidade constituem aspectos integrantes e indissociáveis da educação, na tentativa de definir conceitos e critérios de avaliação da qualidade, distingue a qualidade formal - ligada ao domínio tecnológico - , da qualidade política - voltada para a cidadania - , entendendo que uma não pode ser entendida sem a outra, nem tampouco pode ser substituída pela outra. A qualidade política, referindo-se a conteúdos históricos, é de teor prático e inevitavelmente ideológico e, portanto, de tessitura metodológica distinta daquela que a ciência clássica costuma abarcar em seus cânones. Toca a face social dos valores e compromissos, da consciência social crítica que é capaz de revelar sujeitos autônomos, que não são presas fáceis de manipulações e que estão aptos a fazerem opções sobre 0 uso alternativo das instrumentações tecnológicas. 
Para esse autor, a conotação política da qualidade da escola está menos na sua característica pública do que no controle democrático sobre ela exercido pela comunidade e pela sociedade em geral.

Julga ele necessário também recompor a pesquisa como princípio educativo, uma vez que ela não implica a simples aplicação de métodos científicos de descoberta da realidade, mas responde pelo seu questionamento e transformação. Como princípio educativo, o conhecimento, que tem como fonte privilegiada a pesquisa, está na base do processo emancipatório, que sempre começa com a tomada de consciência crítica e a capacidade de dizer não: ato que inaugura o processo político questionador e que jamais se conclui. 0 confronto de idéias, 0 embate entre posições, o reconhecimento do conflito, a constatação da desigualdade, são fundamentais para a organização política dos desiguais no caminho da emancipação. A importância da escola estaria na sua possibilidade de realizar a dupla face da pesquisa: apetrechar tecnicamente para fundar competência tecnológica e fazer pensar e se repensar na linha da transformação.

Pedro Demo (1995) busca ainda, em outro artigo, caracterizar o compromisso educativo da avaliação escolar e a define como um processo permanente de acompanhamento do aluno. Tendo como referência o paradigma da comunicação, coloca a "discutibilidade" como critério essencial da cientificidade, que tem a ver com a avaliação, tanto no que diz respeito aos procedimentos que fazem parte da sua lógica intrínseca, quanto no que se refere à apreciação da qualidade.

Ana M aria Saul (1992) também adota conceitos afins, sem entre tanto reportar-se explicitamente a essa matriz teórica. A autora propõe um paradigma que qualifica como alternativo: 0 da avaliação emancipatória, que se realiza a partir de três eixos: avaliação democrática, crítica institucional e construção coletiva. Sugere uma classificação política dos estudos avaliativos, visando a construção de uma avaliação democrática, cujos conceitos chave são: sigilo, negociação e acessibilidade, ou seja, direito do usuário à informação e à utilização dos resultados da avaliação para melhorar ou redirecionar as próprias atividades. A crítica institucional e a criação coletiva concretizam-se por meio de três momentos: expressão e descrição da realidade, isto é, elaboração de um diagnóstico institucional e descrição dos dados obtidos; crítica do material expressa pela análise do projeto pedagógico da instituição; criação coletiva, ou seja, delineamento das novas ações da equipe de trabalho. Trata-se de abordagem que envolve pesquisa participante, a qual implica o compromisso do pesquisador com a causa em questão, contribuindo para uma ruptura metodológica profunda. 0 novo paradigma permitiria ao avaliador 
assumir o papel de coordenador dos trabalhos de avaliação, de um orientador dessas ações, favorecendo o diálogo, a discussão, a busca e a análise crítica sobre o funcionamento de um programa.

U ma série de outros textos aborda a avaliação do ponto de vista de suas implicações sociais mais amplas e das relações entre a educação e a sociedade abrangente, valendo-se, para tanto, do referencial crítico-reprodutivista, da pedagogia dos conteúdos, ou da perspectiva que privilegia a instituição escolar e sua cultura como fulcro de análise, e que tem chegado até nós sobretudo pelos escritos de Antonio Nóvoa, Philippe Perrenoud e Gimeno Sacristán.

Esposando este último enfoque, M arli André (1990) considera que a estrutura de poder vigente nas escolas reflete as relações de poder dos órgãos decisórios. Ela é a de um poder predominantemente centralizador, exercido via de regra pelo diretor da unidade, etende a reproduzirse tal e qual na organização do ensino na sala de aula. Para que a prática docente possa ser redimensionada, tornando-se mais justa e mais democrática, recomenda que se implante nas escolas uma sistemática de trabalho menos hierarquizada, mediante a criação de espaços coletivos de reflexão, onde professores e orientadores possam analisar conjuntamente o fazer pedagógico, espaços esses que podem ser utilizados para acompanhamento, avaliação e reformulação do processo de ensino aprendizagem visando ao seu aprimoramento.

A autora discute também a questão do poder e da função social da avaliação escolar, ressaltando a necessidade de analisar as mediações presentes no ato de avaliar. Toma como ponto de partida o conceito de fabricação da excelência escolar de Perrenoud, segundo o qual as normas e os critérios definidos pela escola como de excelência, a despeito de serem frutos de uma dada construção social, são difundidos como a única forma de conceber a realidade. Trabalhar no sentido de uma avaliação mais democrática implica trabal har simultaneamente nos campos da didática, da relação professor-aluno e da organização pedagógica da escola. Envolve também a adoção de uma pedagogia diferenciada que assegure a possibilidade de 0 aluno ser reconhecido pelo grupo independentemente de suas competências escolares e de seu nível cultural. A diferenciação envolve 0 acompanhamento dos processos e dos caminhos de aprendizagem, a busca de estratégias para trabalhar com os alunos mais difíceis, sendo a avaliação formativa a sua principal fonte de informação. Com forte ênfase nos aspectos qualitativos da aprendizagem, o papel desse tipo de avaliação é o de contribuir para esboçar um plano de atuação (1996). 
M enga Lüdke (1995) parte da discussão crítica dos modelos de avaliação comprometidos com a busca de instrumentos de medida "válidos" e "fidedignos", propugnando uma concepção de avaliação fortemente integrada ao próprio processo de ensino aprendizagem, como base para o desenvolvimento de propostas que venham ao encontro das necessidades de alunos e professores. M enciona formas e tentativas de avaliação associadas a esta última concepção. Refere-se ainda à maior confiança que deve ser atribuída à avaliação feita pelos professores e pelos próprio alunos. A despeito de admitir a maior carga de trabal ho envolvida nesse tipo de avaliação, reconhece que ela constitui fator de crescimento que, contudo, não substitui a avaliação baseada em testagens que permitem a comparação de al unos e de instituições, possibilitando a visualização de problemas não apreendidos no nível da sala de aula.

Um grupo de autoras, a saber: M ere Abramowicz (1995), Vera Tavares de Souza (1994), M irian Grinspun (1994 e 1996) e Vera Werneck (1996), propõe uma avaliação holística do aluno, que não se restrinja aos aspectos cognitivos, procurando contemplar sua condição existencial, sentimentos, motivações, valores. Ela deve manter o caráter dinâmico e interativo do processo e aponta para um paradigma denominado crítico-humanista.

Entre os artigos com enfoque psicopedagógico, observa-se que a utilização da teoria psicogenética para analisar a avaliação dos resultados da aprendizagem escolar ocorre dentro de uma perspectiva mais ampla do que em décadas anteriores. A grande popularidade alcançada, tempos atrás, pelas provas operatórias como instrumento de diagnóstico psicope dagógico, é colocada em xeque, posto que a abordagem mais se prestou a preparar as crianças para se saírem bem nos testes, do que propriamente para subsidiar um currículo voltado para o desenvolvimento do aluno nas suas diferentes dimensões do crescimento humano.

Ao invés de tomar esta ou aquela parte da teoria e aplicá-la à avaliação da aprendizagem escolar, os textos procuram apresentar um quadro teórico para a análise do processo de aquisição de conhecimentos na escola, de modo a identificar os problemas mais significativos e a formulá-los com vistas a encontrar soluções relevantes e adequadas. Em um sentido mais amplo, parece que a psicologia e a epistemologia gené ticas vêm sendo utilizadas mais como instrumento de análise dos problemas educacionais, do que consideradas como fonte virtual de soluções para os males que assolam a educação.

0 utros referenciais da psicologia também sugerem novos enfoques para a avaliação. É o caso da Teoria das Inteligências M últiplas, preco- 
nizada por G ardner, e que G ama (1994) comenta como uma abordagem que abre novas possibilidades em educação, propondo perspectivas originais para a avaliação de indivíduos e oferecendo opções que permitem aos educandos realizações pessoais em várias áreas do saber. Para a autora, essa teoria apresenta alternativas para algumas práticas educacionais, especialmente quanto a métodos de avaliação que considerem as inteligências avaliadas, a cultura dos alunos e o desempenho adulto a que se quer chegar. N esse sentido, seria possível mudar o foco nas escolas: de testagem para avaliação; da classificação de alunos para a colaboração com eles na construção de habilidades, com um aproveitamento ideal da variedade de oportunidades educacionais. Propõe, como decorrência da necessidade de avaliar as diferentes inteligências em termos de suas manifestações culturais e ocupações adultas específicas, apontada por $\mathrm{G}$ ardner, que o levantamento de dados sobre o desempenho dos alunos não vise apenas o conhecimento do que foi aprendido, mas como foi aprendido e de que maneira se fará uso de tal aprendizagem.

Em síntese, tal como os demais referenciais das outras áreas de conhecimento, os estudos psicopedagógicos contribuem para a formulação do novo paradigma de avaliação, essencialmente qualitativo, conferindo especial ênfase à avaliação formativa, com insistência num olhar mais descritivo acerca de como operam os mecanismos de aprendizagem e a construção de conhecimentos pelo aluno. 0 eixo desloca-se do produto para o processo da aprendizagem, dando elementos para enten der e trabaIhar o papel do erro na escola; acentua-se o caráter diagnóstico da avaliação; a auto-reflexão do aluno sobre como aprende e o que aprende; a consideração de outras dimensões da avaliação que não a exclusivamente cognitiva; a interatividade no processo avaliativo.

Embora gozando de grande consenso na área, o que vem à tona em relação ao paradigma de avaliação qual itativa é sobretudo a afirmação de certos pressupostos que o fundamentam, tendo sido constatada grande lacuna em termos de sugestões metodológicas e de procedimentos a serem adotados para viabilizá-lo na prática. São muito escassos os textos que se ocupam desses aspectos.

\section{O núcleo duro da avaliação da aprendizagem}

0 outro modelo refere-se a uma tradição recente, mas em franca expansão no país. Ele é objeto de artigos que se reportam, dentro do paradigma positivista, a novas formas de abordagem da avaliação educa- 
cional, sempre em larga escala e, no mais das vezes, animadas por uma particular lógica de implementação das políticas públicas na área.

O s escritos que introduzem modelos e metodologias de avaliação em larga escala nos meios educacionais brasileiros têm a preocupação de, por meio deles, possibilitar o delineamento do perfil cognitivo da população, permitindo reconstituir detalhes da trajetória escolar de populações que freqüentam a escola, bem como identificar a transição de um estágio cognitivo dos sujeitos para outro. Podem ser utilizados também para estabelecer relações entre o perfil cognitivo e cultural de segmentos da população com os novos modelos de organização da produção, bem como com os novos pleitos de participação nas sociedades contemporâneas.

São exemplos de aplicações de modelos de abordagem em larga escala, que se valem de informações educacionais presentes nos censos demográficos, os estudos que empregam a metodologia do profluxo, realizados por Ribeiro (1991), Klein \& Ribeiro (1995) e por Fletcher \& C astro (1993). D emonstrando que o grande problema do sistema educacional brasileiro é a repetência, e sobretudo a repetência nas séries iniciais do ensino fundamental, esses estudos causaram grande impacto nos sistemas de ensino. As políticas de progressão continuada e de aceleração escolar, atualmente tão incentivadas nas redes escolares, certamente devem 0 seu tributo a pesquisas dessa natureza.

A maior parte dos artigos desse grupo volta-se contudo para o que chamamos, no estado da arte, avaliação de monitoramento. Embora essa denominação possa ser associada a outros modos de avaliar, neste caso, em vista da falta de outro termo consensual, a avaliação de monitoramento foi entendida como a avaliação padronizada do rendimento escolar dos alunos, realizada no âmbito federal ou no dos sistemas estaduais de ensino básico.

Para além dos textos examinados no referido estudo, a literatura especializada indica que a montagem de sistemas padronizados de avaliação do ensino que abarquem toda a rede de educação básica é um fenômeno relativamente recente nas sociedades avançadas. Em vários países europeus que os estão implantando, como a $\mathrm{H}$ olanda, França e Inglaterra, apenas nos últimos anos começa-se a dispor de informações completas sobre as primeiras gerações de estudantes que receberam acompanhamento. Embora se tenha buscado invariavelmente associar essa prática aos esforços de melhoria do ensino, observa-se que esse é um terreno ainda muito sujeito a ensaios e erros, a avanços e retrocessos e a controvérsias de toda a ordem. 
O s termos em que foi realizada a sistematização desse modelo de avaliação - amplamente divulgado por meio de organismos multilaterais, em grande parte responsáveis pela adoção de medidas homegeneizadoras em diferentes sistemas escolares do mundo - foram sobretudo pautados pelas reformas educacionais de cunho conservador do início dos anos 80 nos Estados U nidos e do final dessa década e início da seguinte na Inglaterra. Eles foram fundamentais para a promoção de quase-mercados no setor educacional, ou seja, por uma combinação específica de elementos de regulação do Estado e da introdução da lógica de mercado no domínio público, o que aumenta o controle governamental sobre as escolas, ao mesmo tempo em que cria mecanismos de incentivo à competitividade no sistema educacional (Afonso, 1998).

Essas reformas, motivadas pelo argumento de que a qualidade insatisfatória da educação seria basicamente responsável pela vulnerabilidade do país em face do nível educacional e de desenvolvimento de outros países industrializados, partem do pressuposto de que uma força de trabalho educada é crucial para enfrentar a competição econômica, elevando a produtividade e aumentando a capacidade de adaptação às rápidas mudanças nos mercados internacionais. Elas evocam o princípio da accountability como fundamento, ou seja, o de que o poder público deve prestar contas à população dos serviços que oferece e de como gasta os recursos que Ihe foram confiados. Ao fazê-lo, porém, substituem o discurso que val orizava a escola pública em períodos anteriores, revisitando o princípio liberal que coloca ênfase na liberdade de escolha dos pais em relação ao ensino que querem para os filhos, sob a suposição de que eles buscam a melhor educação para as suas crianças. A postam que a melhoria do rendimento dos alunos pode ser alcançada mediante a concorrência entre as escolas, podendo, para tanto, no dizer de Fletcher (1995), valerse da publicidade negativa para estimular administradores e professores a dedicarem maiores esforços ao ensino e utilizar sanções econômicas, políticas, regulamentares como incentivos.

A avaliação nesse modelo ganha importância nunca antes experimentada no cenário educacional, tornando-se componente imprescindível das reformas educativas. Ela permite não só a ampliação do controle do Estado sobre o currículo e as formas de regulação do sistema escolar, como também sobre os recursos aplicados na área. N esse sentido, os imperativos da avaliação terminam por pressionar a formulação de currículos nacionais em países que nunca os tiveram, ou levam à sua reformulação e atualização nos que já os possuíam, visto que eles são a referência "natural" para o emprego da aferição padronizada do rendi- 
mento escolar, instrumento privilegiado do modelo. A avaliação também possibilita que seja conferida uma autonomia vigiada às escolas, uma vez que assegura o controle de seus resultados, e ainda permite que se descentralizem recursos, capazes inclusive de beneficiar escolas privadas que anteriormente não faziam jus a eles, aumentando a capacidade de decisão do Estado sobre sua alocação.

A esse respeito é interessante recuperar o que afirma $\mathrm{H}$ enkel, a propósito da reforma educacional da Inglaterra: a avaliação torna-se importante para "controlar as despesas públicas, mudar a cultura do setor público, e alterar as fronteiras e a definição das esferas de atividade pública e privada" (apud Afonso, p. 162).

$\mathrm{N}$ a América Latina, praticamente todos os países implantaram alguma modalidade de sistema nacional de avaliação do rendimento escolar na última década. O Brasil o fez a partir de 1990, com a criação do Sistema N acional de Avaliação da Educação Básica (SAEB) e de seus congêneres em M inas G erais e São Paulo, além de vir disseminando esse tipo de prática por meio da iniciativa de vários outros estados.

Conforme admite Fletcher (1995), refletindo a propósito de diferentes modelos de avaliação desenvolvidos em alguns estados americanos há mais longo tempo, uma das grandes dificuldades da implementação do sistema a que se fez referência é que ele depende de enorme melhoria na capacidade de processamento da informação. D esse ângulo de análise, trata-se portanto de sistema a ser evitado se a administração não dispuser de fôlego financeiro e competência técnica para geri-lo com os novos recursos da informática. U ma segunda limitação consiste no eventual estreitamento do currículo por iniciativa das escolas que, ao tentarem adaptar-se às novas exigências, podem eliminar os conteúdos que não se relacionem diretamente com os referenciais curriculares básicos. Além disso, nem todas as unidades escolares têm condição de responder aos sinais de mercado preconizados pelo sistema de monitoramento. A circunscrição das matrículas às zonas próximas da escola, tal como acontece em muitas localidades nos Estados U nidos, reduz a capacidade de escolha de melhores escolas pelos pais de alunos. Como lembra 0 autor, nas circunstâncias de monopólio e oligopólio, princípios de livre mercado não são aplicáveis, sendo duvidoso que escolas deficientes tenham iguais oportunidades para responder a incentivos e sanções. Conseqüências possíveis de políticas dessa natureza podem ser a exacerbação de diferenças cognitivas entre as comunidades ricas e pobres, urbanas e rurais, reforçando disparidades sociais existentes. 
Vários estudos realizados nos Estados Unidos e Inglaterra têm igualmente evidenciado as fragilidades da tese de que a livre escolha da escola dos filhos pela família constitui poderoso incentivo à melhoria da qualidade do ensino. O s relatados por H asell e Rothstein em 1993 mostram, entre outras coisas, que a maior parte dos pais de localidades em que foi implantado o sistema, mesmo admitindo como boa a possibilidade de escolherem onde querem matricular os filhos, usualmente não os trocam de escola sendo que, entre os que fazem uso desse direito, não contam grandemente os critérios acadêmicos que supostamente deveriam estar orientando as suas escolhas (apud Campos, 1996).

Embora a avaliação externa, como definida neste texto, seja uma variável crucial no desenho das reformas educacionais em curso em um bom número de países, na transposição do modelo para a América Latina, tanto as justificativas, como as práticas de avaliação, têm, várias vezes e, em certa medida, tentado minorar os aspectos que exacerbam o caráter competitivo da proposta original, dando maior ênfase ao papel compensatório do Estado.

Em documento preparado para a O realc, um grupo de pesquisadores chilenos, ao propor no começo dos anos 90 - portanto após o processo de redemocratização do país -, que a região adote sistemas de medição da qualidade da educação básica, busca associar um novo significado às medidas e à avaliação. N esse caso, o foco está em que a comunidade de atores emita juízos sobre os fenômenos de aprendizagem em que está envolvida e que, a partir deles, desenvolva as ações remediativas que julgar convenientes. Ao lado das medidas padronizadas de aferição de resultados de aprendizagem, buscam contemplar estratégias para a realização de uma avaliação formativa e, partindo do pressuposto de que os recursos são escassos para solucionar problemas de grande magnitude, advogam a importância da avaliação para identificar áreas vulneráveis em que é preciso intervir prioritariamente para melhorar a qualidade do ensino (Filp et al., 1990). A pretensão é a de transformar a avaliação em um instrumento de mudança da realidade educacional, substituindo porém as políticas de corte universalista pelas estratégias particularistas, que visam a atenção a grupos específicos e que vêm se tornando a regra nas políticas da área.

Considerando particularmente a experiência brasileira, vale observar que os aspectos concorrenciais característicos da lógica de mercado podem ser mais facilmente atribuídos aos procedimentos ligados à avaliação de alunos dos cursos superiores, que vêm acompanhados da publicização de resultados e estão fortemente associados aos processos 
de autorização de funcionamento e ao credenciamento desses cursos. No monitoramento dos sistemas de ensino básico, a ênfase tem recaído, via de regra, sobre o uso da informação gerada pela avaliação como subsídio aos próprios aparatos gestores das redes de ensino, prestando-se de preferência a orientar ações do Estado no sentido de suprir necessidades detectadas. Esse é o caso de propostas que incidem sobre a formação dos educadores em serviço, como fruto das deficiências encontradas no desempenho dos alunos do ensino fundamental e médio. Provavelmente a maciça participação do Estado na oferta do ensino básico, pela própria concepção de funcionamento do setor público predominante, crie maiores constrangimentos à implantação da concorrência entre as escolas de uma mesma rede, de vez que elas têm o mesmo mantenedor.

Em experiências mais consolidadas de emprego da avaliação do sistema escolar mediante provas padronizadas na Europa, como, por exemplo, a da $\mathrm{H}$ olanda, país que possui um sistema complexo de subsídio estatal a escolas com diferentes tipos de mantenedores, tem havido grande empenho no envolvimento dos diferentes atores interessados na educação, desde professores, diretores, especialistas e pais, até as universidades e outras entidades da sociedade civil, como os setores empresariais, associações científicas e de trabalhadores. Eles são chamados a ter diferentes tipos de participação, como validar os conteúdos da avaliação e aprovar os procedimentos propostos, colaborar com a realização das provas e contribuir com os encaminhamentos que decorrem dos resultados obtidos.

Q uando os sistemas de avaliação incorporam elementos importantes da cultura escolar e os professores sentem que esta é feita a seu favor e não contra eles, como na Suécia, os procedimentos utilizados terminam sendo assimilados pelos docentes como um indicador importante para a melhoria do seu trabalho. N esses casos, a insistência no caráter complementar das duas modalidades de avaliação, a saber, a padronizada, mais precisa e com condições de comparabilidade, mas necessariamente restrita, e a do professor e da escola, que contempla aspectos mais abrangentes da formação do aluno, parece vir contribuindo para reafirmar junto ao magistério a sua dignidade profissional.

$\mathrm{N}$ a América Latina, as pressões dos organismos internacionais e as linhas de crédito abertas com a finalidade expressa de implantação de sistemas de avaliação padronizada do rendimento escolar têm levado freqüentemente a um superdimensionamento das possibilidades de impacto do uso de informações desse tipo na melhoria da qualidade do ensino. D iante da escassez de recursos e dos altos custos envolvidos na montagem desses sistemas, que não dispensam pesadas contrapartidas 
dos países que recebem tais financiamentos, tem-se por vezes assistido à retração do financiamento às pesquisas educacionais, capazes de trazer aportes não menos valiosos à melhoria do sistema escolar.

Em face da grande quantidade de informações já coletadas em alguns países, seja mediante pesquisas, seja por meio de avaliações padronizadas realizadas em diferentes âmbitos e circunstâncias, perguntase também sobre a capacidade efetiva que teriam os aparatos públicos de ensino de apreciar esses dados e implementar medidas de amplo alcance em decorrência da sua análise. A propósito, recente estudo realizado nos países da região latino-americana corrobora essa indagação ao constatar que, além de debilidades técnicas relativas aos instrumentos de medida e das dificuldades de avaliar adequadamente prendizagens mais complexas, os sistemas nacionais de avaliação vêm demonstrando insuficiente aproveitamento das informações produzidas, do que decorre 0 pequeno impacto nas redes escolares (Ravela, 2000).

É certo que já existe um relativo consenso sobre a necessidade de melhor aparelhar os órgãos gestores dos sistemas escolares para o uso de informações que subsidiem as políticas educacionais, bem como é pacifico o reconhecimento de que urge promover maior articulação entre as instâncias produtoras de conhecimento e aquelas encarregadas de oferecer 0 ensino básico. Entretanto, é preciso que se pondere também sobre os custos envolvidos na geração da enorme quantidade de dados pelos sistemas de informação, em vista das limitações claramente impostas pelos condicionantes da estrutura e funcionamento dos aparatos de ensino, que se ressentem da falta de recursos até mesmo para implementar as medidas educacionais mais básicas.

0 fato de que algumas informações relevantes para mudanças significativas no sistema, já de há muito disponíveis na área, não venham sendo sistematicamente incorporadas às propostas de governo, revela também que a própria opção pela utilização de um tipo de informação e não de outro passa por um crivo político que qualifica ou desqualifica certa natureza de estudos e de dados e torna certas medidas plausíveis ou não, dependendo das forças hegemônicas prevalecentes.

A racionalidade técnica, que pressupõe uma relação de linearidade entre a utilização plena da informação sistematizada nos moldes propostos e a tomada de decisões no âmbito dos complexos sistemas de ensino, não leva em conta o fato de que os resultados de investigações e de pesquisas de avaliação, ao invés de tomados isoladamente como "verdades", constituem tão somente referências acerca de determinados fenômenos, que demandam a consideração das condições sociais, culturais e políticas 
em que ocorrem. É aí que se situam conflitos de interesses, consensos e dissensões que contribuem para amalgamar a formulação e a gestão das políticas educativas. É também nesse contexto que são geradas enormes resistências dentro dos próprios aparatos públicos - até agora pretensamente ignoradas - à divulgação de muitas das informações colhidas por essa via, visto que elas podem ser tidas como ameaças aos mecanismos de legitimação necessários à manutenção das posições de poder.

0 risco da transposição de modelos concebidos nos países avançados para a realidade latino-americana sem que se considere devidamente o fato de que os nossos sistemas de ensino em geral funcionam sob condições de infra-estrutura significativamente mais precárias, pode levar ao desperdício de recursos escassos e escamotear problemas ao invés de representar soluções efetivas para eles.

\section{Impasses e desafios}

A despeito da abundante produção de discursos sobre o tema, constata-se que seus apelos à mudança das práticas escolares e do tratamento tradicional da avaliação terminam tão somente por resvalar a realidade. M esmo quando se chega a ultrapassar o nível do discurso, passando a ações abrangentes nas redes de ensino, como no caso da aval iação de monitoramento, não há ainda evidências de que estejam sendo desencadeadas mudanças significativas no desempenho dos alunos.

Em meio às práticas tradicionais de avaliação, cal cadas na pedagogia do exame en quadradas por fortes dispositivos institucionais de ordenação ainda existentes nas escolas, os professores vêm recebendo apelos sistemáticos para apoiarem dois discursos que se fundam em pressupostos radicalmente distintos. $M$ ais ainda. Aqueles docentes dos estados em que foram implantados sistemas próprios de avaliação de monitoramento estão convivendo, de um lado, com as incertezas e ansiedades que a introdução do modelo nas redes escolares vem causando e, de outro, com a insuficiência de meios para en saiar novas práticas avaliativas de caráter formador, na direção chamada emancipatória.

Um dos discursos reporta-se essencialmente à avaliação qualitativa do ensino, valoriza o processo de aprendizagem, concentra-se na avaliação feita no interior da própria escola pelos atores educacionais. Ele vem sendo reforçado pela expansão do regime de ciclos escolares, cujos pressupostos são o de garantir a continuidade da escolarização sem as rupturas provocadas pela repetência e o de possibilitar a criação de condições para que a escola trabalhe diferentemente com a diversidade dos alunos. 
0 outro discurso propõe-se a oferecer indicadores da qualidade do ensino, volta-se para a apreciação de resultados padronizados, valoriza o produto da aprendizagem, utiliza largamente recursos quantitativos e alta tecnologia e recorre à avaliação externa do rendimento escolar. Assenta-se, por sua vez, na apreciação exclusiva de alguns aspectos cognitivos do currículo, deixando de lado dimensões da formação do educando não só muito valorizadas socialmente, como incorporadas nas próprias diretrizes do ensino.

Embora sejam reconhecidas, na origem, matrizes políticas e ideológicas inconciliáveis entre as duas postulações, e ainda que se admita que no processo de sua reapropriação pelos sistemas de ensino, ambas possam chegar a adotar uma série de procedimentos e recomendações comuns e complementares, a prática tem mostrado a necessidade de retomar a função reguladora e a função emancipadora da avaliação a partir de nova ótica.

Se, para além do Estado e do mercado, forem também levadas em conta as aspirações mais gerais da população a respeito da educação, não meramente atreladas a razões de ordem estritamente econômica, mas fundamental mente ligadas à qualidade de vida, ou como diria Boaventura Santos (apud Afonso, 1998), "ao prazer, à participação, à solidariedade", talvez seja possível deixar de imputar tão somente à ênfase no processo um caráter "progressista" e parar de atribuir à insistência nos resultados um caráter exclusivamente conservador da avaliação.

D o ponto de vista da função educacional da escola, a ênfase no processo e nas condições gerais em que é oferecido o ensino torna-se condição essencial para que educadores, alunos e as próprias instituições educacionais usufruam do potencial redirecionador da avaliação, não só no sentido de potencializar condições para um efetivo domínio dos conhecimentos pelos estudantes, como para uma formação que se estende a outras esferas. N ão obstante, do ponto de vista da população usuária dos serviços educacionais, a quem não interessam diretamente os processos internos dos estabelecimentos escolares, são os resultados apresentados pelos alunos aqueles que se prestam à validação social das funções exercidas pela escola. $M$ as, se esses resultados não se prendem a uma racionalidade científico-instrumental apenas, será preciso repensá-los na perspectiva que busca romper com o conceito de regulação atribuído ao conhecimento e à avaliação.

Recebido para publicação em junho de 2001. 


\section{BRASILIAN BASIC EDUCATION: \\ TWO DIFERENT APROACHES FOR EVALUATION}

ABST RACT: Thistext aimsto analysetheapproches claimed for evaluation on brasilian basic education. It comments some conclusions from a State of Art about academic articles on the theme during the $90 \mathrm{~s}$, and adds other reflections. According to the author, two approches have been taking up the discurse on evalution in the country: one of them refers to its emancipatory potential and the other takes roots in the regulatory function of the state. The article seeks to examine both visions in terms of their theoretical and ideol ogical matricesand to discussissues that followsfrom them. It concludes by theneed to rethink the regulatory and emancipatory functions of evaluation, adopting other theoretical perspective.

Key words: Evaluation; Assessment; Basic education; Educational quality; Public policy.

\section{Referências bibliográficas}

ABRAM OWICZ, M. Avaliação da aprendizagem de trabalhadoresestudantes: Buscando novos caminhos. Estudos em Avaliação Educacional, São Paulo, jan./jun. 1995, no 11, p.113-123.

AFO N SO , A.J. Políticas educativas e avaliação educacional. Braga: U niversidade do M inho, 1998.

ANDRÉ, M.E.D.A. de. A avaliação na escola e da escola. Cadernos de Pesquisa, São Paulo, ago. 1990, № 74, p. 68-70.

. Avaliação escolar: Além da meritocracia e do fracasso. Cadernos de Pesquisa, São Paulo, nov. 1996, no 99, p.16-20.

BARRETTO, E.S. de S. e PINTO, R.P. (Coords.). Estado da arte: Avaliação na educação básica. São Paulo: Fundação Carlos Chagas; Brasília: Inep/ Comped/PN UD, 2000.

CAM POS, M .M .M. Resenha. H asell \& Rothstein (orgs). School choice: Examining the evidence. Revista Brasileira de Educação, São Paulo, set./dez. 1996, no 3, p.103-106.

DEM O, P. Lógica e democracia da avaliação. Ensaio, Rio de janeiro, jul./set. 1995, № 8, vol. 3, p. 323-330.

. Q ualidade da educação: Tentativa de definir conceitos e critérios de avaliação. Estudos em Avaliação Educacional, São Paulo, jul./dez. 1990, no 2, p.11-26. 
FLET CH ER, P. Propósitos da avaliação educacional: Uma análise das alternativas. Estudos em Avaliação Educacional, São Paulo, jan./ jun.1995, no 11, p.93-112.

FLETCHER, P. \& CASTRO, C. de M . M itos, estratégias e prioridades para 0 ensino de primeiro grau. Estudos em Avaliação Educacional, São Paulo, jul./dez.1993, no 8, p. 39-56.

FILP, J. et al. Sistema de medición de la calidad de la educación básica: Una propuesta. Estudos em Avaliação Educacional, São Paulo, jul./ dez. 1990, no 2, p. 49-90.

FRAN C O, M .L.B. Pressupostos epistemológicos da avaliação educacional. Cadernos de Pesquisa, São Paulo, ago. 1990, no 74, p. 63-67.

Q ualidade de ensino: C ritérios e avaliação de seus indicadores. İdéias, São Paulo, 1994, no 22, p. 81-87.

GAM A, M.C. A teoria das inteligências múltiplas ou a descoberta das diferenças. Ensaio, Rio de Janeiro, jan./mar. 1994, vol.1, № 2, p. 13-20.

GRISPU N , M . Avaliação da educação, cidadania e trabalho. Ensaio, Rio de Janeiro, jan./mar. 1996, vol. 4,no 10, p. 71-76.

Paradigmas em educação: Avaliação e perspectivas. Ensaio, Rio de Janeiro, jan./mar. 1994, vol. 1, no 2, p. 29-40.

KLEIN, R. \& RIBEIRO, S.C. A pedagogia da repetência ao longo das décadas. Ensaio, Rio de Janeiro, jan./mar. 1995, vol. 3, no 6, p. 55-62.

LU CKESI, C. Avaliação da aprendizagem escolar: Apontamentos sobre a pedagogia do exame. Tecnologia Educacional, Rio de Janeiro, jul./ ago.1991, vol. 20, no 101 , p. 82-86.

Avaliação educacional: Pressupostos conceituais. Tecnologia Éducacional, Rio de Janeiro, maio/ago.1996, vol. 25, no 130-131, p. 26-29.

Planejamento e avaliação na escola: Articulação e necessária determinação ideológica. Idếas, São Paulo, 1992, no 15, p. 115-125.

LÜDKE, M. 0 administrador escolar entre o mito da avaliação e os desafios de sua prática. Estudos em Avaliação Educacional, São Paulo, jul./dez. 1995, no 12, p. 51-57. 
RAVELA, P. et al. H acia donde y como avanzar en la evaluación de aprendizajes en América Latina? U mbral 2000, Digital, no 3, mayo 2000. D isponível em: htttp://www.reduc.cl.

RIBEIRO, S.C. A pedagogia da repetência. Estudos em Avaliação Educacional, São Paulo, jul./dez. 1991, no 4, p. 73-86.

SAU L, A.M . Avaliação emancipatória: U ma abordagem crítico-transformadora. Tecnologia Educacional, Rio de Janeiro, jan./fev. 1992, vol. 21, no 104, p. 24-31.

SOUZA, V.T. Avaliação de aprendizagem. Ensaio, Rio de Janeiro, abr./ jun.1994, vol.1, no 3. p. 13-20.

WERN ECK, V.R. A velha e a nova questão da avaliação. Ensaio, Rio de Janeiro, out./dez. 1996, vol. 4, no 13, p. 371-380. 